\title{
Virtual Motor Control for the Machine Tool Table with Three Linear Servo Motors
}

\author{
Keisuke UMEZAWA ${ }^{1}$, Yasuhiro KAKINUMA ${ }^{1}$, Seiichiro KATSURA ${ }^{2}$, Kohei OHNISHI ${ }^{1}$, \\ Tojiro AOYAMA ${ }^{1}$, Katsuhiko YOKOI ${ }^{3}$ \\ ${ }^{1}$ Graduate School of Integrated Design Engineering, Keio University, Japan, \\ k-umezawa@ina.sd.keio.ac.jp, kakinuma@sd.keio.ac.jp, aoyama@sd.keio.ac.jp \\ ${ }^{2}$ Nagaoka University of Technology, ${ }^{3}$ Brother Industries, LTD.
}

\begin{abstract}
:
The linear motor driving mechanism has been adopted as a positioning mechanism of machine tools to realize high speed and precise positioning due to the absence of friction and backlash. However, when two or more linear motors are used, minute differences between the thrust forces of each motor causes the generation of micro vibration and the change of velocity of each linear motor due to yawing around the center of gravity. This study proposes a virtual motor control method that uses three linear motors for the driving table to control the position of the center of gravity, bending and yawing independently.
\end{abstract}

Keywords: Motion control, Machine tools, Feedback control, Feedforward control, Disturbance observer

\section{Introduction}

Due to recent progress, high driving speed and precise positioning is demanded in machine tools; especially, the demand of positioning accuracy is very high in order to produce products with a high accuracy and high speed. The ball screw drive, an established mechanism of the feed drive, is usually applied to the machine tool table. With this drive, friction and backlash generated at the screw nut leads to a decrease in the machining accuracy. Therefore, because it does not generate friction and backlash, the linear motor driving mechanism has been adopted as a positioning mechanism for machine tools instead the ball screw drive to realize high speed and precise positioning. When the machine tool table is driven at high speed, two or more linear motors are installed in parallel for single-axis driving to obtain a high thrust force. When more linear motors are used, however, a posture change of the table occurs because the thrust force of each linear motor is not the same. In addition, this difference of the thrust force generates micro vibration and changes the velocity of each linear motor due to yawing around the center of gravity (COG). In this study, a virtual motor control method is proposed for a table drive system with three linear motors that control the position of the center of gravity, the bending and the yawing independently.

\section{Principle of two-axis and three-axis linear motor driving mechanism}

In a conventional table driving system with linear motors, only one linear encoder is installed on a single axis, even if two or more linear motors are applied. Therefore, it is impossible to control the effect of bending and yawing on the posture of the table. If the position of each linear motor can be measured by an encoder installed in each motor, it is possible to control the posture of the table. For example, by using two linear motors and two linear encoders, yawing generated around the COG can be controlled, as illustrated in Fig. 1. Moreover, when the table is driven by three linear motors with three linear encoders, as shown as Fig. 2, it becomes possible to control not only the yawing but also the bending of table so that the micro vibration induced by bending can be suppressed if the sampling frequency of control system is higher than natural frequency of machine tool table.

\section{Structure of the table system}

In this study, a table system driven by three linear motors, each on a single axis, is developed. Figure 3 shows a photograph of the table driven with three linear motors. The weight of the table is $9.8 \mathrm{~kg}$, and it is supported by two linear guides of an antifriction bearing set at the front side and back side. Figure 4 shows a schematic diagram of the table system. A linear encoder is set for each linear motor so that each position and velocity

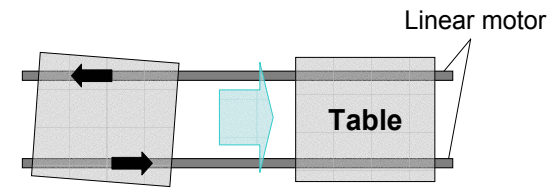

Figure 1: Two axis motor driving

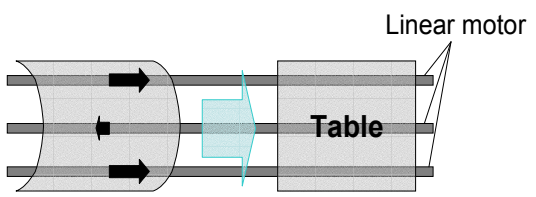

Figure 2: Three axis motor driving

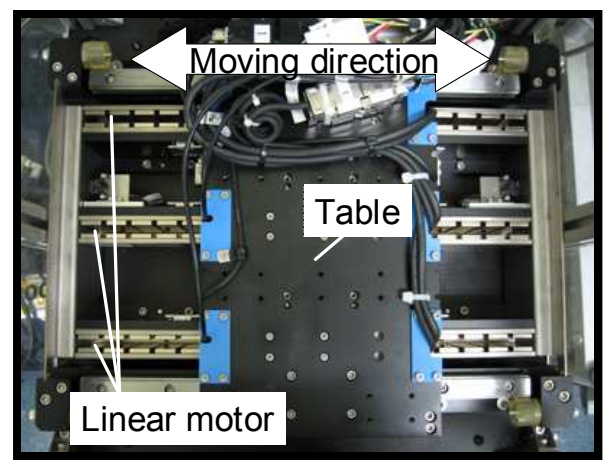

Figure 3: The appearance of driving table with three linear motors 
of each linear motor can be measured through the encoder count board. Then the measured position and velocity of the three motors are fed back to the controller and the command values are calculated. The command signal is changed from a digital signal to an analog signal through the $\mathrm{A} / \mathrm{D}$ Board.

\section{Virtual motor control method}

The virtual motor control method is a new technique for applying a virtual motor defined according to the workspace of the control system. The virtual motor is an actuator controlled by the virtual motor controller, which regulates each mode, that is, the center of gravity (COG), the bending and the yawing. Figure 5 shows the position coordinates of each motor, and the position of the COG, bending and yawing, which are described as follows.

$$
\begin{aligned}
g & =\frac{x_{1}+x_{2}+x_{3}}{3} \\
d & =\frac{x_{1}+x_{3}}{2}-x_{2} \\
\theta & =\frac{x_{1}-x_{3}}{L}
\end{aligned}
$$

Where $g$ is the position of the COG, $d$ is the amount of bending, $y$ is the amount of yawing, $L$ is the total length between the three motors, and $x_{1}, x_{2}, x_{3}$ are the positions of the three motors. In this study, each mode is defined as follows.

$$
\left(\begin{array}{l}
x_{g} \\
x_{d} \\
x_{\theta}
\end{array}\right)=Q\left(\begin{array}{l}
x_{1} \\
x_{2} \\
x_{3}
\end{array}\right) \quad Q=\left(\begin{array}{ccc}
1 & 1 & 1 \\
1 & -2 & 1 \\
1 & 0 & -1
\end{array}\right)
$$

Where $Q$ is given by formulas (1)-(3).

The command signal is sent to an actual linear motor by converting the position of each mode to each actual position of the linear motor, as given in equation (5).

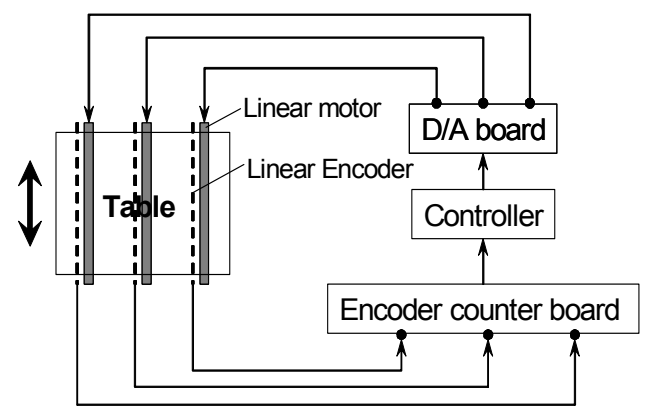

Figure 4: Schematic diagram of table system

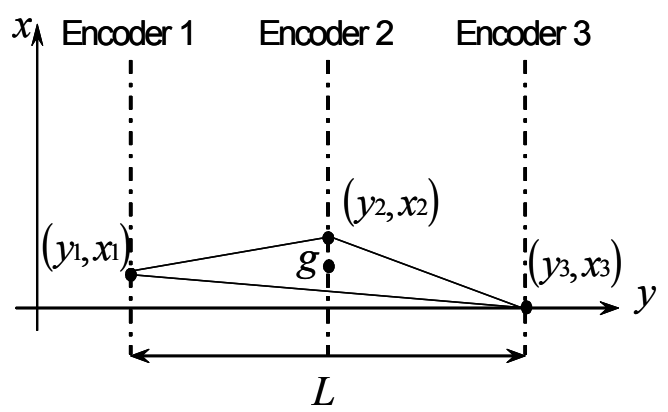

Figure 5: Position coordinates of each encoder

$$
\left(\begin{array}{l}
x_{1} \\
x_{2} \\
x_{3}
\end{array}\right)=Q^{-1}\left(\begin{array}{l}
x_{g} \\
x_{d} \\
x_{\theta}
\end{array}\right) \quad Q^{-1}=\frac{1}{6}\left(\begin{array}{ccc}
2 & 1 & 3 \\
2 & -2 & 0 \\
2 & 1 & -3
\end{array}\right)
$$

By direct control of the virtual motor, the three modes do not interact with each other. Therefore, it becomes possible to control each mode independently with this method.

To evaluate this method, the virtual motor control is simulated as shown in Fig. 6. The parameters used in this simulation are listed in Table 1. From the result, it is confirmed that the position of each mode can be controlled. In addition, the response of yawing can be improved without interaction with the other two modes when the yawing gain of the virtual motor controller increases.

\section{Application of feedforward control method and disturbance observer}

In order to improve the responsivity of the position and compensate the disturbance error perfectly, feedforward control and disturbance observer are applied in the

\begin{tabular}{|c|c|c|c|}
\hline & Sampling time & 1.0 & $\mathrm{~ms}$ \\
\hline & $\begin{array}{l}\text { Command value of COG mode } \\
\text { Amplitude } \\
\text { Frequency } \\
\text { Command value of bending mode } \\
\text { Command value of yawing mode }\end{array}$ & $\begin{array}{r}10.0 \\
1.0 \\
5.0 \\
2.5\end{array}$ & $\begin{array}{l}\mathrm{mm} \\
\mathrm{Hz} \\
\mathrm{mm} \\
\mathrm{mm}\end{array}$ \\
\hline $\begin{array}{l}K_{p 1} \\
K_{v 1}\end{array}$ & $\begin{array}{l}\text { Position control gain of COG mode } \\
\text { Velocity control gain of COG mode }\end{array}$ & $\begin{array}{r}25.0 \\
100.0 \\
\end{array}$ & \\
\hline $\begin{array}{l}K_{p 2} \\
K_{v 2}\end{array}$ & $\begin{array}{l}\text { Position control gain of bending mode } \\
\text { Velocity control gain of bending mode }\end{array}$ & $\begin{array}{r}25.0 \\
100.0 \\
\end{array}$ & \\
\hline $\begin{array}{l}K_{p 3} \\
K_{\text {v3 }} \\
\end{array}$ & $\begin{array}{l}\text { Position control gain of yawing mode } \\
\text { Velocity control gain of yawing mode }\end{array}$ & $\begin{array}{c}5.0 \\
20.0,1\end{array}$ & $\begin{array}{l}25.0, \quad 50.0 \\
100.0,200.0\end{array}$ \\
\hline$g_{d i s}$ & $\begin{array}{l}\text { Cut-off frequency of } \\
\text { disturbance observer }\end{array}$ & 700.0 & $\mathrm{rad} / \mathrm{s}$ \\
\hline
\end{tabular}
proposed control system. Figure 7(a) shows a block diagram of the feedback controller. The transfer function $\mathrm{G}$ from the command position to the response position in

Table 1: Parameters for virtual motor control simulation

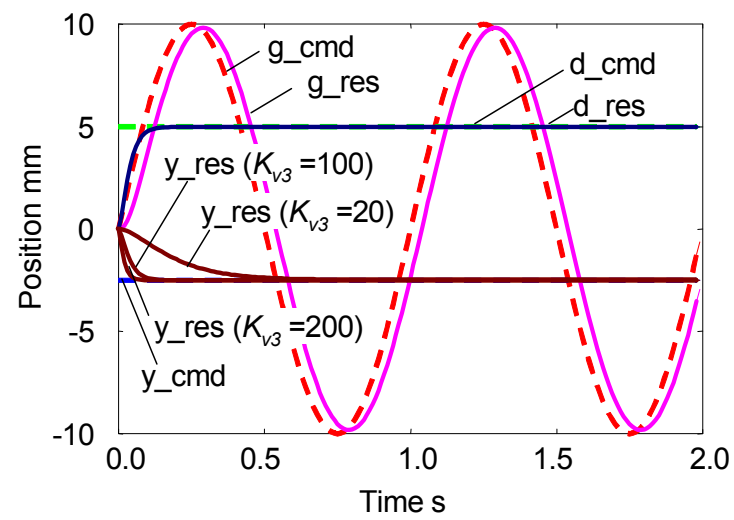

g: position of the center of gravity $\mathrm{d}$ : amplitude of vibration, $y$ : yawing cmd: command, res: response

Figure 6: Simulation result of virtual motor control 
the feedback system is described as

$$
G(s)=\frac{x^{\text {res }}}{x^{\text {cmd }}}=\frac{K_{p} K_{v}}{s^{2}+K_{v} s+K_{p} K_{v}}
$$

where $K_{p}$ is the position control gain, $K_{v}$ is the velocity control gain, $x^{\text {res }}$ is response position, $x^{\text {cmd }}$ is command position, and the parameter $s$ is in general complex.

This system generates a second-order time lag of response, as shown in the simulation result of Fig. 8. To improve the time lag of response, a feedforward control, illustrated in Fig. 7(b), is applied. The feedforward system can be realized by giving the velocity and acceleration in the input command. By applying the feedforward control, the transfer function between input and output becomes,

$$
G(s)=\frac{x^{r e s}}{x^{c m d}}=\frac{s^{2}+K_{v} s+K_{p} K_{v}}{s^{2}+K_{v} s+K_{p} K_{v}}=1
$$

Equation (7) indicates that the response value delay. As shown in Fig. 9, the responsivity improves remarkably.

In addition, a disturbance observer, represented in Fig. 10, was designed. By using the disturbance observer, it becomes possible to estimate the disturbance error with high accuracy and to perfectly compensate for it. Figure 11 shows the effect of the disturbance observer by a simulation. When a constant disturbance is applied to this system after $1.0 \mathrm{~s}$, the change of position caused by the disturbance is immediately compensated by the disturbance observer. Moreover, by setting a higher gain of the disturbance observer, the effect of suppression against the position error is improved without interaction of the main control system. In order to obtain these effects, the proposed virtual motor system is combined with the feedforward and the disturbance observer, as shown in Fig. 12 .

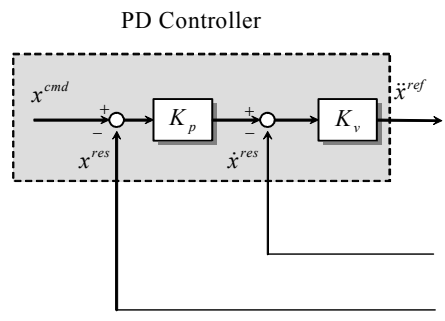

a) Feedback controller

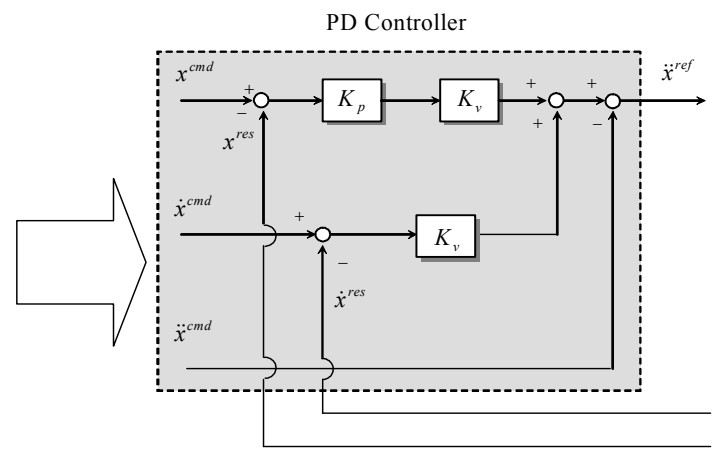

b) Feedforward controller

Figure 7: Block diagram of feedback controller and feedforward controller

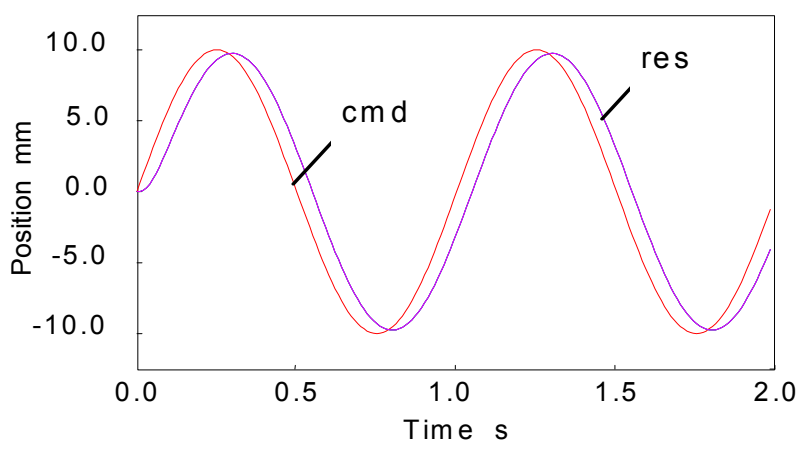

Figure 8: Simulation result of feedback control

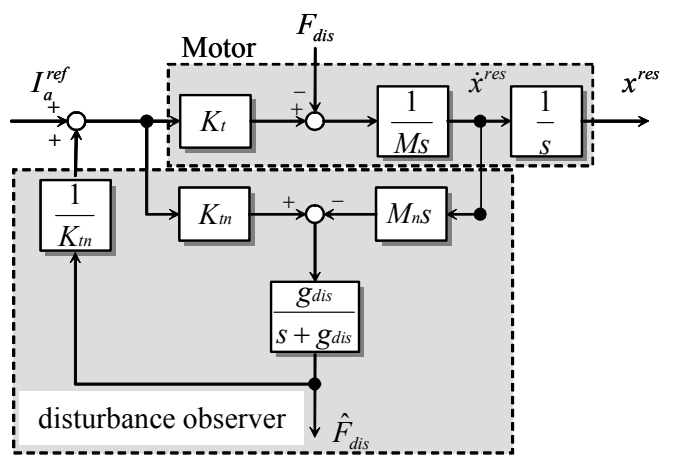

Figure 10: Block diagram of disturbance observer corresponds with the command value at all times without

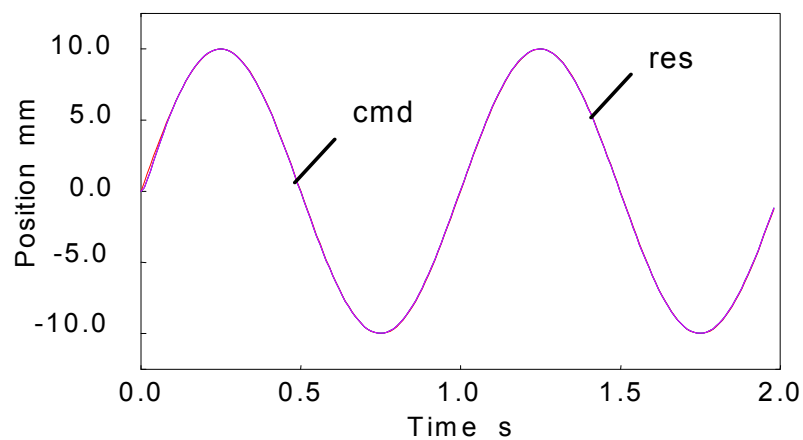

Figure 9: Simulation result of feedforward control

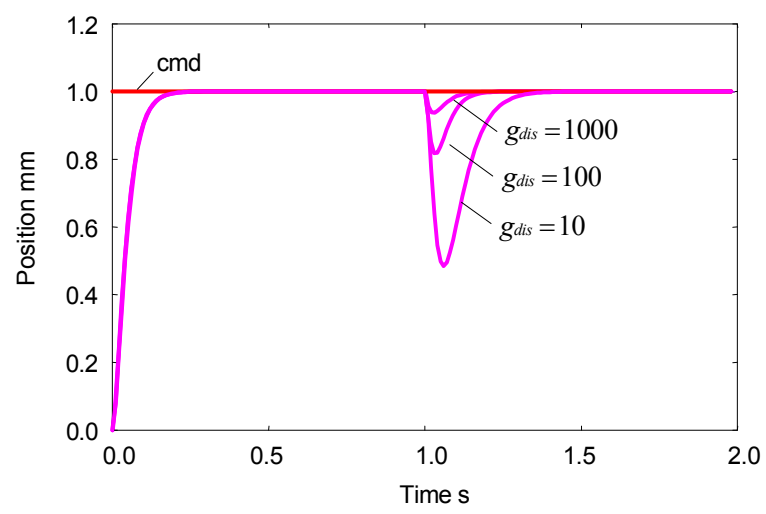

Figure 11: Effect of disturbance observer 


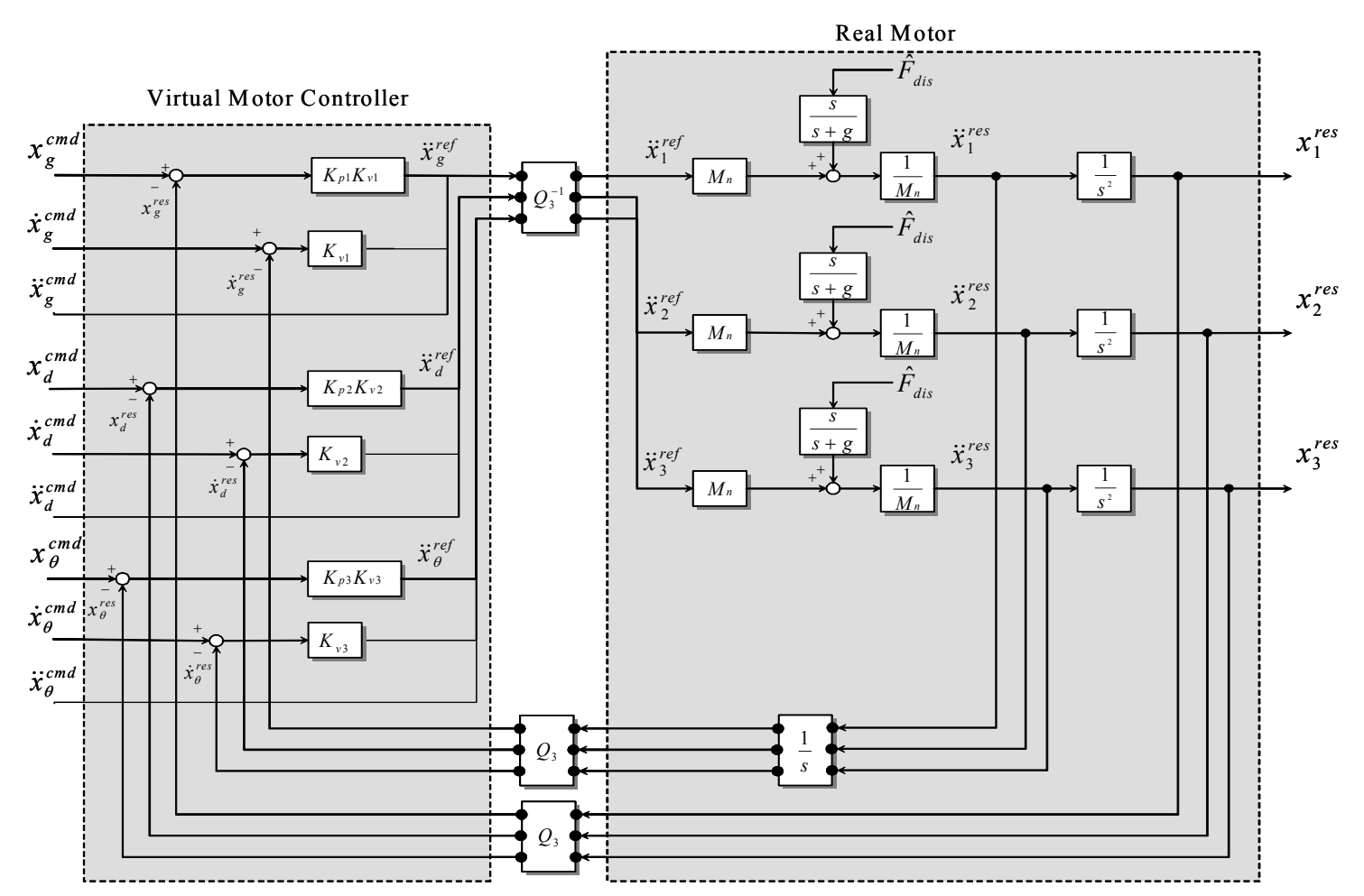

Figure 12: Block diagram of whole system

\section{Experiment}

\subsection{The experiment using the step response test}

In order to evaluate the effect of bending and yawing suppression, a step response test was carried out with both the virtual motor control method and the real motor control method to directly control the positions of the three linear motors. The control parameters are listed in Table 2. The results of the step response test are shown in Fig. 13-15. No difference in the response position of the COG between the virtual motor and real motor control is observed. On the contrary, the amount of bending and yawing is effectively suppressed by using the virtual

Table 2: Experimental parameter of real motor control and virtual motor control

\begin{tabular}{|c|c|c|c|}
\hline \multicolumn{4}{|c|}{ Common parameter } \\
\hline & Sampling time & 1.0 & $\mathrm{~ms}$ \\
\hline$g_{\text {dis }}$ & $\begin{array}{l}\text { Cut-off frequency of } \\
\text { disturbance observer }\end{array}$ & $\begin{array}{l}700.0 \\
\mathrm{rad} / \mathrm{s}\end{array}$ & \\
\hline \multicolumn{4}{|c|}{ Real motor control } \\
\hline & Command value & 10.0 & $\mathrm{~mm}$ \\
\hline$K_{p}$ & Position control gain & 80.0 & \\
\hline$K_{v}$ & Velocity control gain & 320.0 & \\
\hline \multicolumn{4}{|c|}{ Virtual motor control } \\
\hline & Command value of COG mode & 10.0 & $\mathrm{~mm}$ \\
\hline & Command value of bending mode & 0.0 & $\mathrm{~mm}$ \\
\hline & Command value of yawing mode & 0.0 & $\mathrm{~mm}$ \\
\hline$K_{p 1}$ & Position control gain of COG mode & 80.0 & \\
\hline$K_{v 1}$ & Velocity control gain of COG mode & 320.0 & \\
\hline$K_{p 2}$ & Position control gain of bending mode & 80.0 & \\
\hline$K_{v 2}$ & Velocity control gain of bending mode & 320.0 & \\
\hline$K_{p 3}$ & Position control gain of yawing mode & 80.0 & \\
\hline$K_{v 3}$ & Velocity control gain of yawing mode & 320.0 & \\
\hline
\end{tabular}

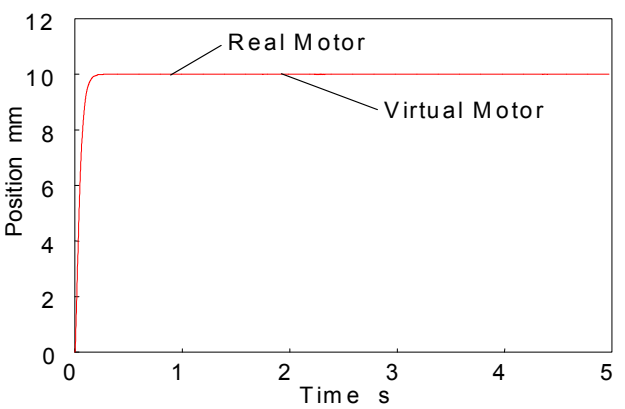

Figure 13: Result of COG mode in step response

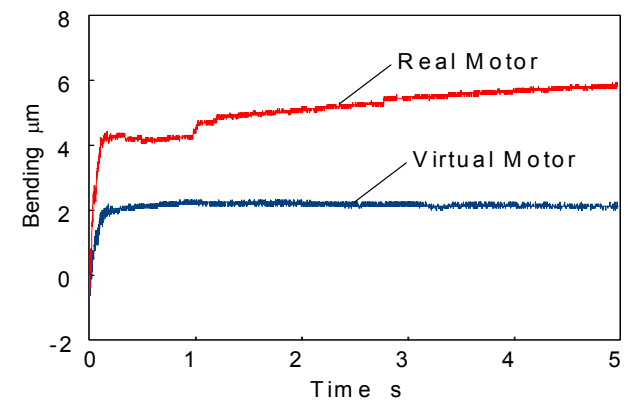

Figure 14: Result of bending mode in step response

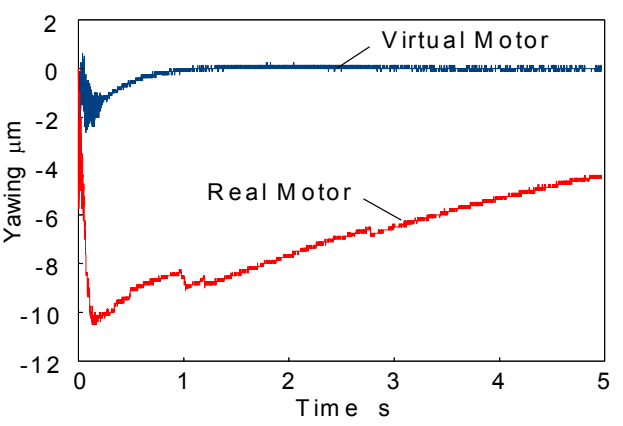

Figure 15: Result of yawing mode in step response 
motor control because the bending mode and yawing mode can be controlled independently. However, in this system, only quasi-static deformation of machine tool table can be controlled because sampling frequency is lower than natural frequency of bending mode which is approximately $300 \mathrm{~Hz}$ in this table.

In addition, by giving the command value of the yawing mode, as shown in Table 3, it becomes possible to deliberately generate yawing. Figure 16 shows the comparison of the yawing response between the yawing mode gain $K v_{3}$ of 40 and 80 . As a result, yawing is generated according to the command of the yawing mode. Moreover, the responsivity of the yawing mode to the command is improved when the yawing mode gain is set higher.

\subsection{Evaluation of independent control}

In order to investigate the independency of each mode, a step response test was carried out under various experimental conditions, shown in Table 4. Figure 17 shows a comparison of each mode response for case A and case B. There is no difference of the response position in both the COG mode and bending mode because of the same gains set in the COG mode and bending mode as the experimental conditions of case $\mathrm{A}$ and case $\mathrm{B}$. On the other hand, the suppression effect of yawing is considerably different. Similarly, Fig. 18 shows a comparison of the responses for case $\mathrm{A}$ and case $\mathrm{C}$; here, it is possible to control the bending mode independently. From these results, it is clearly possible to design the responsiveness of each mode independently in the virtual motor control system because each mode does not interact with each other. This advantage makes the gain tuning of the controller considerably easier.

\subsection{The experiment for evaluation of the feedforward effect using the frequency response test}

A frequency response test was carried out to compare the responsivity of the feedback control and feedforward control. Figure 19 shows the position response of the COG with respect to the sinusoidal command using feedback control and feedforward control. The frequency response characteristics of feedback control and feedforward control are shown in Fig. 20. It is apparent that responsivity is improved by applying feedforward control.

\subsection{Influence of thrust force saturation}

The thrust force is limited by a servo drive controller not to exceed $125 \mathrm{~N}$. However, when the mechanical assembly of the table system is not suitable, the thrust force tends to increase more and more due to the effect of the disturbance observer, and then the thrust force becomes saturated. This causes the increase of micro vibration and yawing because of the lack of control during saturation of thrust force. The influence of thrust force in the responses of the bending mode and yawing mode is shown in Fig. 21-22. Figure 21 shows the response with thrust force saturation, and Fig. 22 shows the response without thrust force saturation. In both figures, (a) shows the response of bending and yawing, and (b) shows the response of thrust force.
Table 3: Experimental parameters of virtual motor

\begin{tabular}{l|l|ll}
\hline \multicolumn{3}{c}{ Virtual motor control } \\
\hline & Command value of COG mode & 0.01 & $\mathrm{~m}$ \\
& Command value of bending mode & 0.0 & $\mu \mathrm{m}$ \\
& Command value of yawing mode & 2.0 & $\mu \mathrm{m}$ \\
\hline$K_{p 3}$ & Position control gain of yawing mode & 10.0, & 20.0 \\
$K_{v 3}$ & Velocity control gain of yawing mode & $40.0,80.0$ \\
\hline
\end{tabular}

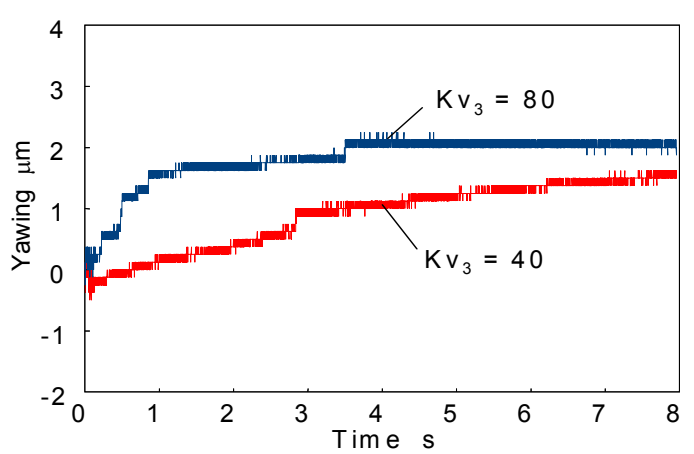

Figure 16: Result of yawing mode

Table 4: Experimental parameters used in evaluation of independent control

\begin{tabular}{l|ll}
\hline \multicolumn{3}{c|}{ Command value } \\
\hline Command value of COG mode & 0.01 & $\mathrm{~m}$ \\
Command value of bending mode & 0.0 & $\mu \mathrm{m}$ \\
Command value of yawing mode & 0.0 & $\mu \mathrm{m}$ \\
\hline
\end{tabular}

\begin{tabular}{c|c|c|c}
\hline \multicolumn{4}{|c}{ Controller gain } \\
\hline case & $\mathrm{Kp}_{1}, \mathrm{Kv}_{1}$ & $\mathrm{Kp}_{2}, \mathrm{Kv}_{2}$ & $\mathrm{Kp}_{3}, \mathrm{Kv}_{3}$ \\
\hline $\mathrm{A}$ & 20,80 & 80,320 & 80,320 \\
\hline $\mathrm{B}$ & 20,80 & 80,320 & 20,80 \\
\hline $\mathrm{C}$ & 20,80 & 20,80 & 80,320 \\
\hline
\end{tabular}

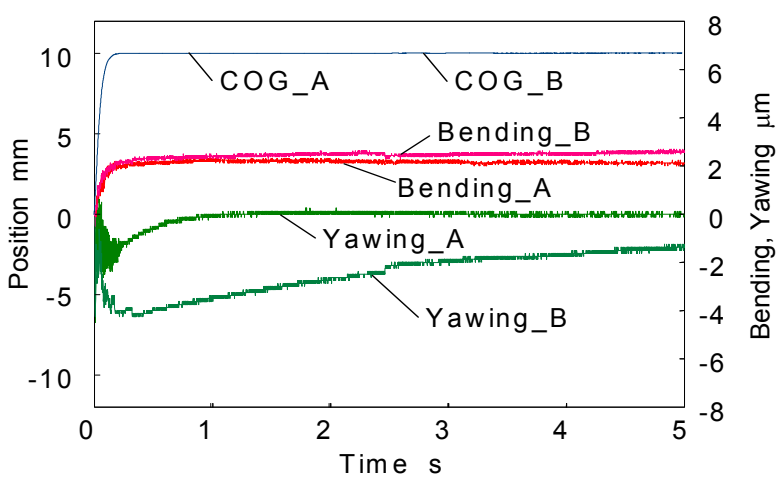

Figure 17: Comparison of each response between case A and case B

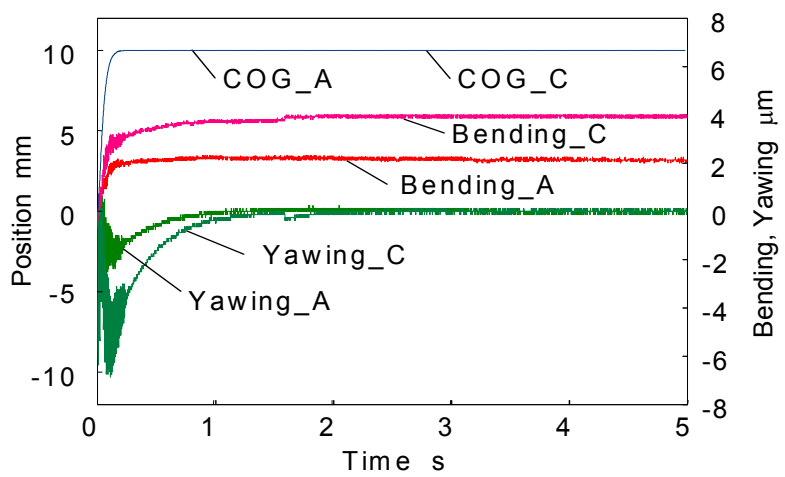

Figure 18: Comparison of each response between case $A$ and case $C$ 


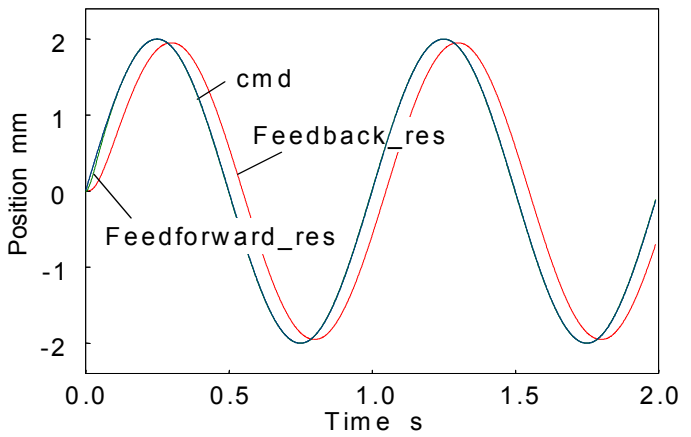

Figure 19: Comparison of responsivity between feedback control and feedforward control

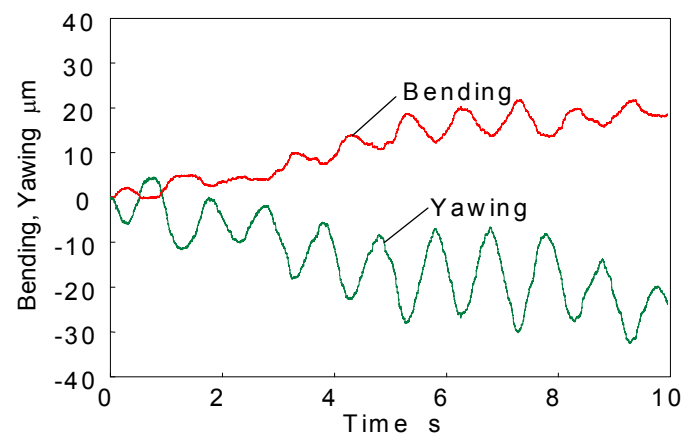

(a) Response of bending mode and yawing mode

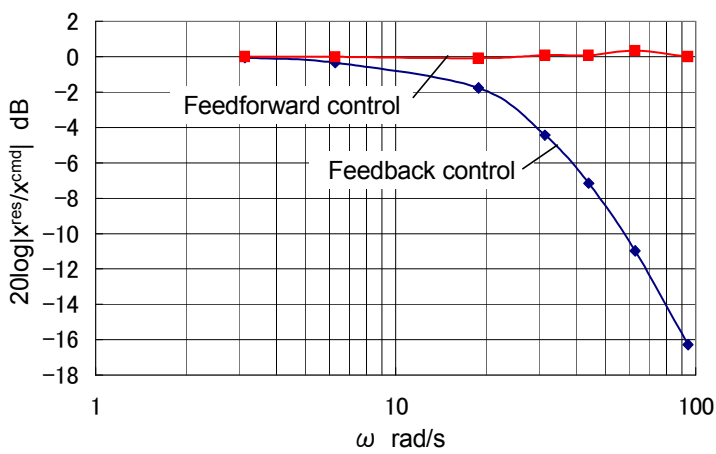

Figure 20: Frequency characteristics of feedback control and feedforward control

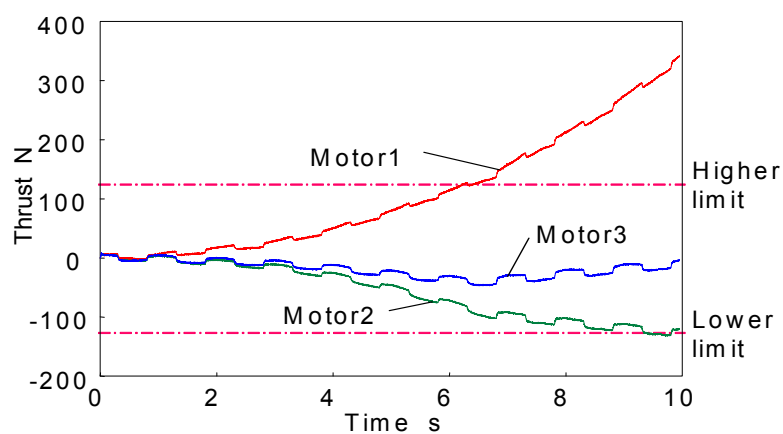

(b) Thrust force response of each motor

Figure 21: Result with thrust force saturation

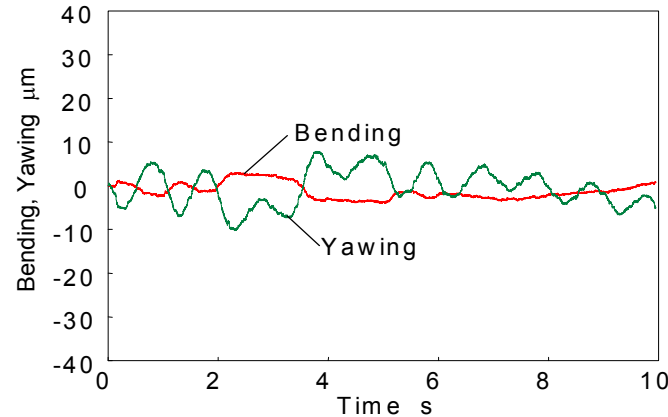

(a) Response of bending mode and yawing mode

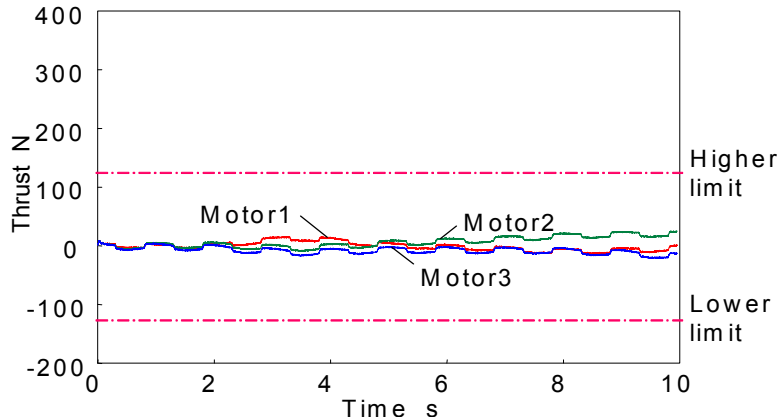

(b) Thrust force response of each motor

Figure 22: Result without thrust force saturation

These results indicate that the bending and yawing mode cannot be controlled when the thrust force is saturated. Therefore, it is necessary to prevent thrust force saturation for control of the bending and yawing modes.

\section{Conclusion}

In order to control the position of the center of gravity, the bending and the yawing independently, a virtual motor control method was proposed that uses three linear motors for the driving table. From the results of simulation and experiments, it is confirmed that the three modes are controlled independently and, therefore, bending and yawing can be suppressed by using virtual motor control. Moreover, by combining the virtual motor control method with the disturbance observer and feedforward control, this control system has high robustness, and high speed can be realized. Finally, to realize the suppression of bending and yawing, it is necessary to consider the influence of thrust force on the responses.

\section{References}

[1] Kohei OHNISHI, 1993, Robust Motion Control by Disturbance Observer, Journal of the Robotics Society of Japan, Vol.11, No.4, pp. 486-493.

[2] Seiichi KATSURA et al., 2004, Quarry of Environmental Information Based on Twin Robot System Environment Quarrier, The 8th IEEE International Workshop on Advanced Motion Control, pp. 243-248.

[3] Guilherme Jorge MAEDA et al., 2005, Control of an XY Nano-Positioning Table for a Compact Nano-Machine Tool, International Conference on Leading Edge Manufacturing in 21st Century, Vol.3, pp. 987-992.

[4] Seiji HASHIMOTO et al., 2004, Ultra-Precision Stage Control Based on Friction Model of Non-Resonant Ultrasonic Motor, The 8th IEEE International Workshop on Advanced Motion Control, pp. 559-564. 